\title{
Coaxial Rotor Flow Phenomena in Forward Flight
}

\author{
Natasha Barbely \\ NASA Ames Research Center \\ Professor Narayanan Komerath \\ Georgia Institute of Technology
}

\begin{abstract}
Coaxial rotors are finding use in advanced rotorcraft concepts. Combined with lift offset rotor technology, they offer a solution to the problems of dynamic stall and reverse flow that often limit single rotor forward flight speeds. In addition, coaxial rotorcraft systems do not need a tail rotor, a major boon during operation in confined areas. However, the operation of two counter-rotating rotors in close proximity generates many possible aerodynamic interactions between rotor blades, blades and vortices, and between vortices. With two rotors, the parameter design space is very large, and requires efficient computations as well as basic experiments to explore aerodynamics of a coaxial rotor and the effects on performance, loads, and acoustics. In this study, the Harrington/Dingeldein rotor forward flight test case from the 1950s is simulated using the incompressible Rotor Unstructured Navier-Stokes (RotUNS) CFD to predict performance and flow field properties using moment um source modeling. Flow field properties from RotUNS are used to investigate coaxial rotor wakes and blade-blade aerodynamic interactions. To further underst and these aerodynamic interactions, a simplified OVERFLOW simulation of two airfoils traveling in opposite directions aided the understanding of the pressure field behavior of a coaxial rotor in hover to capture compressible blade crossing effects. A MatLab-based simulation of a coaxial rotor system that generates two super-imposed undistorted rotor wakes is used to estimate the times and locations of blades overlaps and blade-vortex interactions.
\end{abstract}

\section{Introduction}

Coaxial rotor aircraft are finding increasing interest in civil and military applications, as well as in the small, unmanned aerial vehicles (UAVs) market. Compared to single-main rotor or tiltrot or configurations, however, there are only limited studies, analytical or experimental, on coaxial rotors. Studies on coaxial rotor performance are highlighted below.

Coleman [1] provides a summary of experimental and analytical studies of coaxial rotors through 1997. The first documented U.S. coaxial rotor test was a hover test by Taylor in 1950 [2] in the fullscale wind tunnel at NASA Langley Research Center. The coaxial rotor consisted of two 20-in diameter rotors, with two blades per rotor. The test objective was to visualize the flow through several (single, coaxial, tandem) rotor configurations with and without a ground plane present.

Page 1 of 10
A surprisingly small number of coaxial rotor hover experiments have been performed since the Taylor test, with the work by Ramasamy [3] being the most comprehensive. Ramasamy measured the performance of single, coaxial, tandem, and tiltrotor configurations using untwisted and twisted blade sets. The coaxial rotor system comprised two independent test rigs allowing separate performance measurements of the upper and lower rotor. More recently, Cameron et al. [4] measured the performance of a single rotor and coaxial rotor system in hover using an 80-in diameter rotor with unt wisted blades. Hub loads and blade deformation were also measured. The recent dat a from the Sikorsky X2 [5] flight test joins the handful of forward flight measurements since 1997 not included in the Coleman survey.

Analysis of coaxial rotor systems has progressed over the last decade thanks to improved modeling capabilities. Barbely et al. [6] summarizes computational efforts focusing on coaxial rotor systems. The main objective of Barbely et al. [6] was to investigate the flow field of a coaxial rotor system in hover and forward flight using the incompressible hybrid-CFD analysis tool RotUNS. The present effort continues the work of Barbely et al., with the goal of understanding the blade passing effects and the interactions of the two rotor wakes. While RotUNS was used for 3D simulations, a simplified 2D simulation of two airfoils traveling in opposite directions was simulated using OVERFLOW. The OVERFLOW simulations were used to capture compressible blade crossing effects not captured in RotUNS. To estimate the times and locations of blade overlaps and blade-vortex interactions, a MATLAB-based simulation of a coaxial rotor system that generates two super-imposed undistorted rotor wakes was developed. The OVERFLOW and MATLAB simulations helped deconstruct the 3D flow field predicted by RotUNS.

\section{Methodology}

\section{Harrington Single Rotor 1 (HS1) and Coaxial Rotor 1 (HC1) Geometry}

The performance and aerodynamics of the Harrington single rotor 1 (HS1) and coaxial rotor 1 (HC1) were predicted using RotUNS in forward flight.

The geometry for $\mathrm{HS} 1 / \mathrm{HC} 1$ is provided in Table 1; the blade planform as modeled in RotUNS is shown in Fig. 1. The difference in the blade geometry for the HS1 and HC1 Harrington experiment [7] and RotUNS is that the Harrington blades have a continuously varying non-linear distribution of airfoil thickness. At this time, RotUNS does not allow such a thickness distribution, so nine NACA 
airfoils with varying thickness ratios were used to simulate the blade for HS1 and HC1. C81 airfoil tables were interpolated for changing $\mathrm{r} / \mathrm{R}$ location to determine $\mathrm{c}_{1}$ and $\mathrm{c}_{\mathrm{d}}$. The $\mathrm{C} 81$ tables were generated using a 2D Navier-Stokes solver and were used for all RotUNS calculations in this paper.

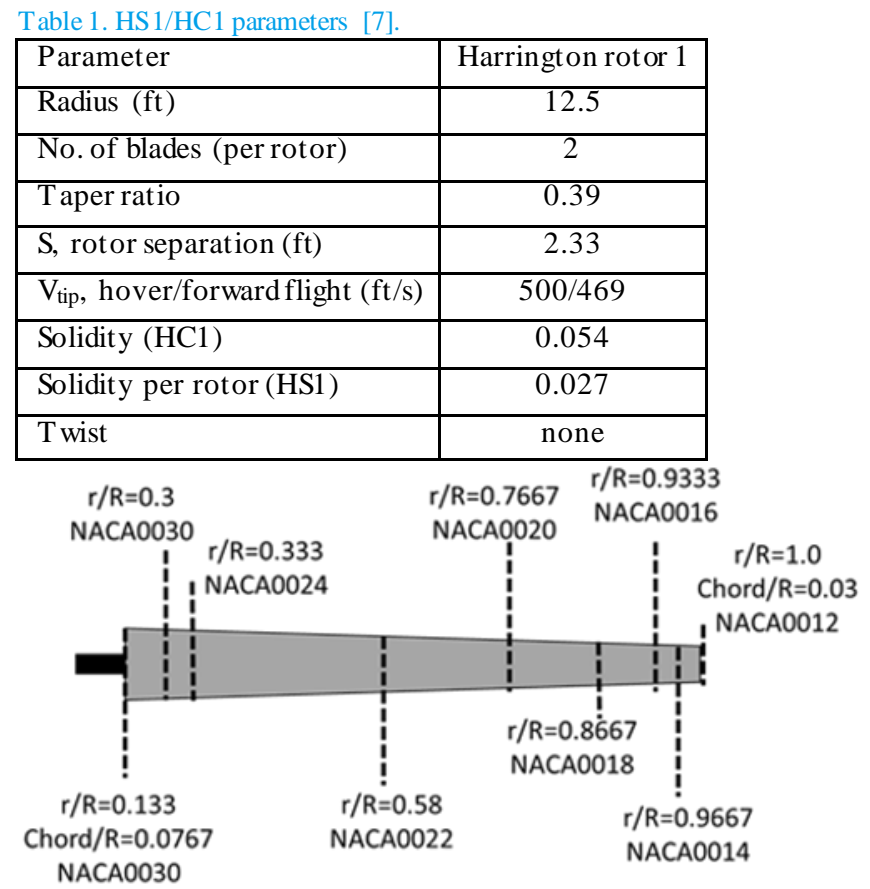

Figure 1. HS1/HC1 blade planform geometry as modeled in RotUNS.

\section{Rotor Unstructured Flow Solver (RotUNS)}

RotUNS operates within the RotCFD Integrated Design Environment (IDE) $[9,10]$. RotCFD offers a bridge between comprehensive rotorcraft analysis and CFD individual (discrete) blade analysis. RotUNS is one of several flow solvers within RotCFD, which includes a geometry module, a semi-automated grid generation module, a rotor module, and a flow visualization and analy sis module, all integrated in one environment. Operating within the RotCFD IDE, grid generation and problem set -up are quickly executed, facilitating parametric sweeps of rotor conditions and geometries. RotCFD balances ease of use and practical resource constraints with accurate physical representation of the global flow field.

RotUNS solves the 3D incompressible Reynolds-Averaged NavierStokes (RANS) equations using an unstructured grid in the far field $[9,10]$. T wo options are available to model the rotor: the discrete blade source model (DBM) and the distributed source model (DSM). Both options rely on user provided tables of two-dimensional airfoil coefficients for a range of angle-of-attack and Mach number values. Using the computed velocity field and blade element momentum theory, the local angle of at ack and Mach number at each blade element section are computed and the aerodynamic coefficients are retrieved from the airfoil tables. For the DBM, the section forces and moments are then converted to source terms that are added to the momentum equations at grid points where the blade intersects, while DSM consists of a disk of momentum sources.

Unlike the DSM, the DBM comprises an individual lifting-line representing each blade. The lifting-line changes location with time. In order to calculate time-varying rotor sources, the instantaneous

Page 2 of 10 location of each rotor blade is found, followed by calculation of the time-accurate rotor force that the blades exert on specific regions of the flow. Each rotor blade is divided into approximately 100 source locations and the azimuthal position of the blade is assumed to be periodic (constant RPM).

At each time step, the starting and ending azimuthal position s of a rotor blade are computed and used to find coordinates of the blade sections and intersections with the grid cells. Rotor sources are computed similarly to the DSM and added to the momentum equations for the grid cell. The solution is then advanced in time.

Barbely et al. [6] calculated hover and forward flight performance predicted using the DSM of RotUNS. This paper continues that work by analyzing the flow field in forward flight using the DBM. The rotors are trimmed using the trim solutions from CAMRAD II, a rotorcraft comprehensive analysis. CAMRAD II is used to calculate performance, loads, vibration, stability, and response for wide range of rotary wing vehicles [12].

\section{OVERFLOW}

For a coaxial rotor each rotor operates in the induced flow field produced by the other. As a first step toward understanding this complex, 3D, time varying flow field in hover, a 2D unsteady simulation of two airfoils traveling in opposite directions was performed using OVERFLOW.

OVERFLOW [11], developed by NASA, is a compressible Reynolds-Averaged Navier-Stokes CFD analysis tool that uses overset grids. Unlike RotUNS, OVERFLOW can accommodate moving grid and the actual geometry of the blade is modeled.

All airfoil crossing OVERFLOW calculations used the following numerical schemes: ARC3D diagonalized Beam-Warming scalar pentadiagonal scheme for the left hand side and central difference Euler terms for the right hand side. The spacing of off-body grids is set to ds $=0.40$ chord lengths. For both the upper and lower airfoil the number of grid points around each airfoil is 253 and 65 in the normal direction. The spacing between the surface of the airfoil and first grid point is $1.0 \times 10^{-6}$ chord lengths and the distance to the far-field boundaries (DFAR) is 400 chord lengths.

\section{BUNNI-BITE}

Unlike a 2D simulation, the exact time of blade overlap of two contra-rotating rotors with more than one blade each requires careful accounting. Therefore, the code BITE (Blade Intersection Timing Extractor) was developed to predict the time and location of blade overlap. BITE is a MATLAB [13] code that identifies the time and azimuth at which a reference blade of the upper (or lower) rotor crosses a lower (or upper) rotor blade. BITE aids in pinpointing locations of interest between or in the plane of the rotors.

The upper and lower rotors can have different parameters including: RPM, number of blades, blade phase location, reference blade, radius, and chord. Though a constant RPM and blade phasing was used for the upper and lower Harrington coaxial rotor, results become less intuitive when the parameters for each rotor differ.

The BITE code was then modified for 3D analysis by incorporating an identifier for interactions between the upper rotor tip vortices and lower rotor blades. The tip vortex trajectory is modeled using a single 
rotor with a rigid (or undistorted) wake model in descending flight [14]. The model was modified for a coaxial rot or by adding an additional lower rotor location with opposite rotational direction. The model does not account for rotor-rotor wake interaction. The addition of the BVI identifier is called BUNNI (Blade UNdistorted wake Numerical Identifier). The wake model depends on advance ratio and inflow $\lambda i$, which will be modified for more accurate results at a later time.

\section{Results}

RotUNS calculations of HS1 and $\mathrm{HC} 1$ performance are presented first, followed by a detailed study of the aerodynamic interactions of the $\mathrm{HC} 1$ coaxial rotor system. Both BUNNI-BITE and RotUNS are used to estimate locations and times of blade overlap and bladevortex intersections of $\mathrm{HC1}$. The OVERFLOW simulations of the two airfoils traveling in opposite directions are used to corroborate the basic physics of the 3D flow field produced by RotUNS. Finally, the overall $\mathrm{HC} 1$ wake geometry produced by RotUNS is studied and in particular, the wake skew angle is compared with a simple analysis.

\section{Performance}

For forward flight predictions, trim settings for the $\mathrm{HC} 1$ rotor were required. Here, RotUNS relied on trim control solutions provided by CAMRAD II [12]; the settings are provided in Table 2 and Table 3 for $\mathrm{HS} 1$ and $\mathrm{HC1}$, respectively for a trim target of balanced torque.

Table 2: HS 1 forward flight RotUNS inputs using CAMRAD II control settings [12]

\begin{tabular}{|c|c|c|c|c|}
\hline$\mu$ & $\alpha s\left({ }^{\circ}\right)$ & $\theta\left({ }^{\circ}\right)$ & $\theta 1 s\left({ }^{\circ}\right)$ & $\theta 1 c\left(^{\circ}\right)$ \\
\hline 0.12 & -2.18 & 7.31 & -2.51 & 0.63 \\
\hline 0.14 & -2.87 & 7.50 & -2.93 & 0.48 \\
\hline 0.16 & -3.66 & 7.82 & -3.37 & 0.38 \\
\hline 0.18 & -4.53 & 8.27 & -3.87 & 0.32 \\
\hline 0.20 & -5.48 & 8.83 & -4.41 & 0.25 \\
\hline 0.22 & -6.49 & 9.51 & -5.03 & 0.21 \\
\hline 0.24 & -7.57 & 10.33 & -5.73 & 0.17 \\
\hline
\end{tabular}

Table 3: HC1 forward flight RotUNS inputs using CAMRAD II control settings [12].

\begin{tabular}{|c|c|c|c|c|}
\hline$\mu$ & $\alpha s\left({ }^{\circ}\right)$ & $\theta\left({ }^{\circ}\right)$ & $\theta 1 s\left({ }^{\circ}\right)$ & $\theta 1 c\left(^{\circ}\right)$ \\
\hline \multicolumn{5}{|c|}{ Lower rotor } \\
\hline 0.12 & -2.16 & 7.98 & -2.43 & 1.32 \\
\hline 0.14 & -2.85 & 8.03 & -2.89 & 0.99 \\
\hline 0.16 & -3.64 & 8.27 & -3.35 & 0.81 \\
\hline 0.18 & -4.51 & 8.67 & -3.85 & 0.69 \\
\hline 0.20 & -5.47 & 9.19 & -4.36 & 0.63 \\
\hline 0.22 & -6.46 & 9.85 & -5.07 & 0.55 \\
\hline 0.24 & -7.53 & 10.65 & -5.75 & 0.5 \\
\hline Upper rotor & & & \\
\hline 0.12 & -2.16 & 8.07 & -2.75 & 1.05 \\
\hline 0.14 & -2.85 & 8.08 & -3.12 & 0.84 \\
\hline 0.16 & -3.64 & 8.31 & -3.55 & 0.69 \\
\hline 0.18 & -4.51 & 8.69 & -4.03 & 0.59 \\
\hline
\end{tabular}

Page 3 of 10

\begin{tabular}{|c|c|c|c|c|}
\hline 0.20 & -5.47 & 9.21 & -4.57 & 0.5 \\
\hline 0.22 & -6.46 & 9.87 & -5.19 & 0.42 \\
\hline 0.24 & -7.53 & 10.68 & -5.9 & 0.36 \\
\hline
\end{tabular}

Figure 2 shows the measured forward flight performance of HS1 and HC1 [8] compared to CAMRAD II and RotUNS DSM and DBM calculations. Less than $1.3 \%$ difference is seen between DSM and DBM RotUNS calculations for both HS1 and HC1 RotUNS performance calculations. RotUNS calculations for HS1 are closer to the experiment al dat a compared to CAMRAD II calculations, while CAMRAD II calculations for $\mathrm{HC} 1$ are closer to experimental data compared to RotUNS HC1 calculations.

The two analyses use different airfoil distributions with RotUNS providing an airfoil thickness distribution that is more represent ative of the rotor [8, 12]. For each airfoil, a 2D Navier-Stokes analysis was used to generate airfoil tables that were read by RotUNS. An increment to the section profile drag was added as part of the shaft power calculation in CAMRAD II. Since the control inputs used in RotUNS are not directly coupled with the resulting aerodynamic solution within RotUNS but rather are from the aerodynamic model within CAMRAD II, the resulting differences in the required shaft power between CAMRAD II and RotUNS are expected. A natively coupled trim capability within RotUNS is expected to improve the RotUNS calculations. The computed torque from RotUNS for the upper and lower rotor torque for each advance ratio differed by less than $0.50 \%$.

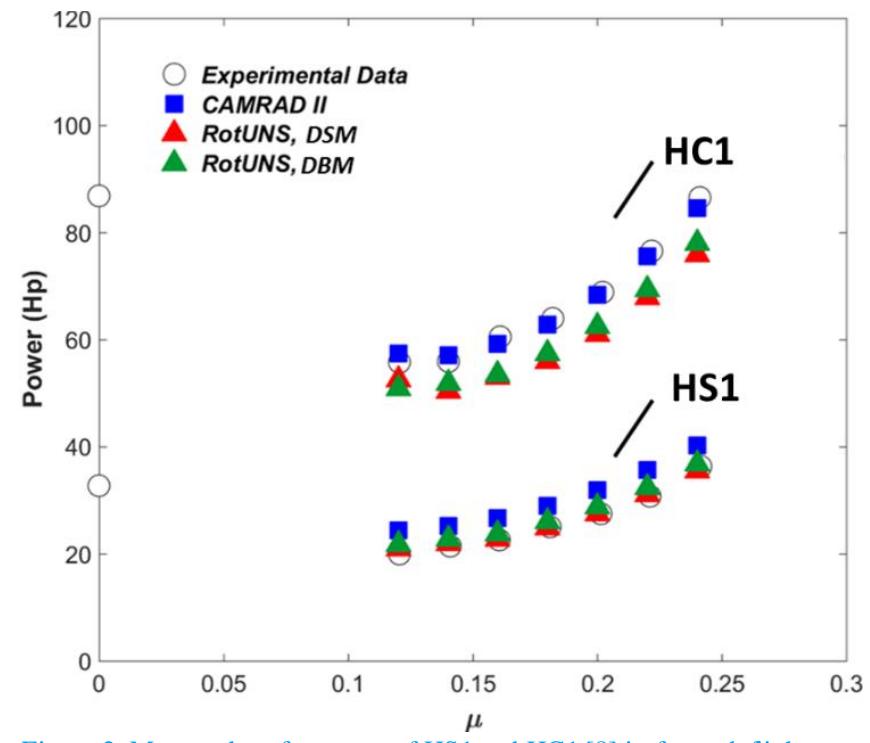

Figure 2: Measured performance of HS1 and HC1 [8] in forward flight compared with CAMRAD II, RotUNS DSM and DBM calculations.

\section{Blade-blade and Blade-vortex interactions}

A simplified analysis of the coaxial rotor wake system was performed first. The exact time of blade overlap of two contra-rotating rotors, each with more than one blade, requires careful accounting. BUNNIBITE predicts not only the time and location of blade overlap, but also possible blade vortex interactions. For example, the reference blade is identified by first selecting the upper or lower rotor and then selecting the blade. A blade crossing is recorded when a reference blade and a blade from the other rotor overlap. For a coaxial rotor with two blades per rotor (rotating in opposite directions), the code 
predicted 4 overlaps of the reference blade in one rotor revolution. Figure 3 is an isometric view of the $\mathrm{HC} 1$ for $\mu=0.12, \mathrm{~S}=2.33 \mathrm{ft}$, $\chi_{T P P}=80^{\circ}, C_{T}=0.0050$ and $\alpha_{s}=-2.16^{\circ}$ at a) 0 revolutions and b) 1 revolution.

The starting location (Fig. 3a) for each blade is as follows: U1, ref. (upper rotor blade 1) is at $0^{\circ}, \mathrm{U} 2$ (upper rotor blade 2) is at $180^{\circ}, \mathrm{L} 1$ (lower rotor blade 1) is at $90^{\circ}$, and L2 (lower rotor blade 2) is at $270^{\circ}$. The lower rotor blades overlap with $\mathrm{U} 1$, ref. in the following order for one revolution (Fig. $3 \mathrm{~b}$ ): $\mathrm{L} 1$ at $45^{\circ}, \mathrm{L} 2$ at $135^{\circ}, \mathrm{L} 1$ at $225^{\circ}$ and $\mathrm{L} 2$ at $315^{\circ}$.

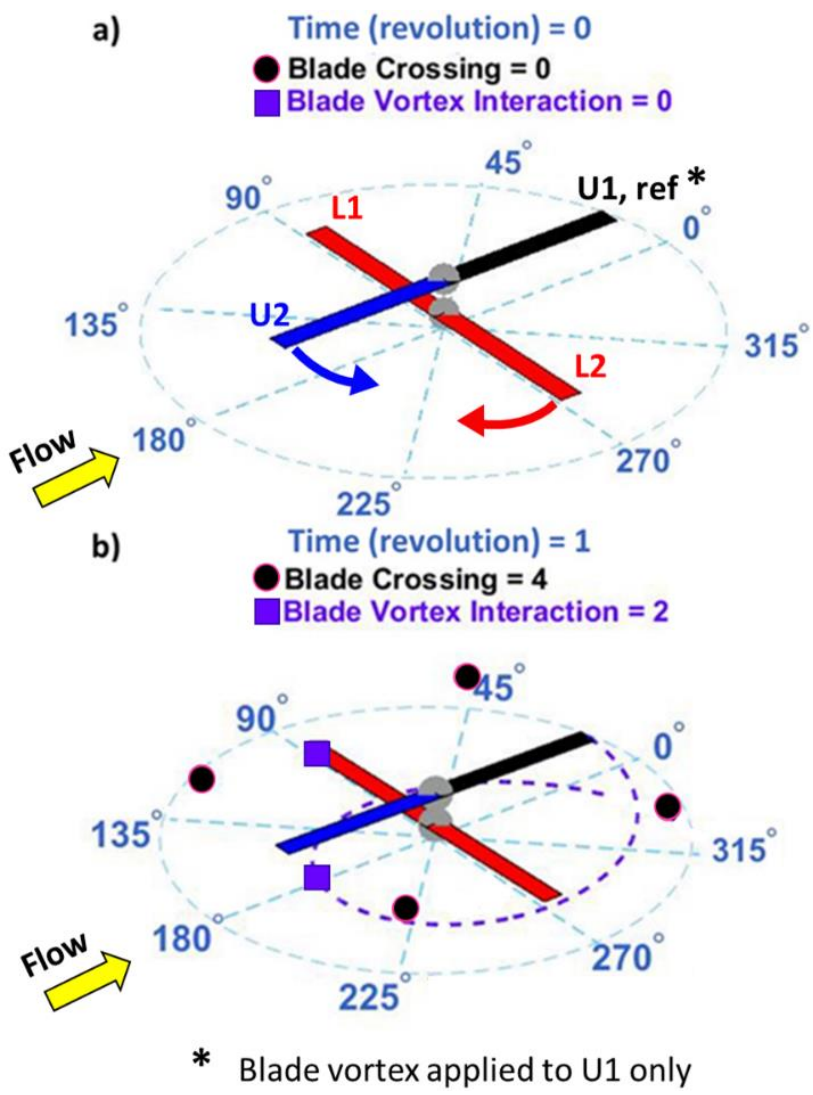

Figure 3: BUNNI-BITE simulation for a 2-bladed coaxial rotor in descent $\left(\mathrm{V}_{\mathrm{tip}}\right.$ $=469 \mathrm{ft} / \mathrm{s}, \mu=0.12$, and $\left.\mathrm{S}=2.33 \mathrm{ft}, \chi_{T P P}=80^{\circ}, \mathrm{CT}=0.0050, \alpha \mathrm{S}=-2.16^{\circ}\right)$, at two different times: a) 0 revolutions and b) 1 revolution.

BUNNI-BITE identifies when a blade crossing occurs and if and when an upper rotor blade vortex interacts with a lower rotor blade. The azimuth angle at which the upper rotor blade tip vortex interacts with a lower rotor is also identified. For this condition, BUNNI-BITE predicted 2 BVI instances, with a tip vortex trailed from U1 only and 4 blade crossings. The graphical representation in Fig. 3 is plotted in Fig. 4.
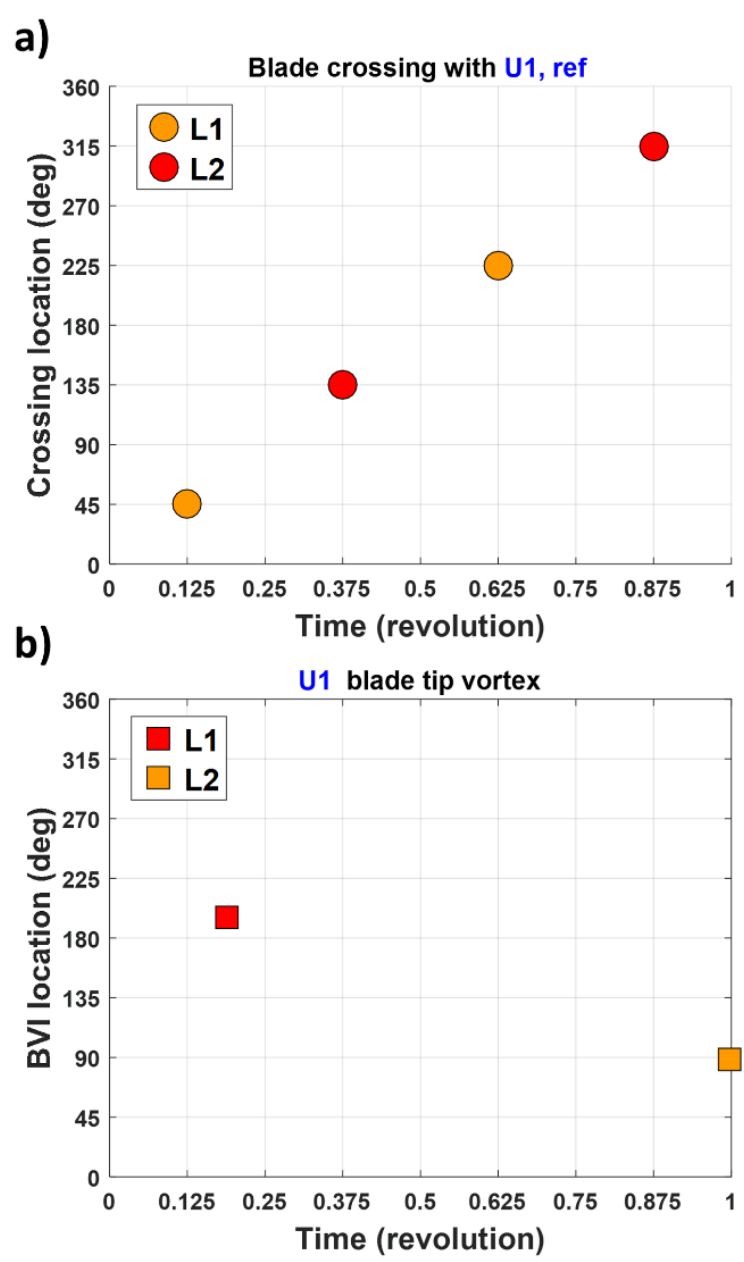

Figure 4: Predictions for a 2-bladed coaxial rotor in descent a) blade crossing time and location, reference blade $=\mathrm{U} 1$ and, b) BVI of lower rotor blades $\left(\mathrm{V}_{\mathrm{tip}}\right.$ $=469 \mathrm{ft} / \mathrm{s}, \mu=0.12$, and $\mathrm{S}=2.33 \mathrm{ft}, \chi_{T P P}=80^{\circ}($ RotUNS calculated $), \mathrm{C}_{\mathrm{T}}=$ $\left.0.0050, \alpha_{\mathrm{s}}=-2.16^{\circ}\right)$

The pressure above and below a rotor in forward flight at $\mu=0.12$ is analyzed using the discrete-blade option of RotUNS. HS1 was analyzed first and then $\mathrm{HC} 1$. Control settings for $\mathrm{HS} 1$ and $\mathrm{HCl}$ are shown in Table 2 and Table 3.

The pressures above and below the rotor(s) are shown in Figs. 5 - 7, which represent the absolute pressure normal to the plane of the rot or at the closest flow field grid point for $\mathrm{HS} 1$ and $\mathrm{HC1}$. 
a)

b)

$\mathrm{U} 1, \mathrm{U} 2=0^{\circ}, 180^{\circ}$

$\mathrm{L} 1, \mathrm{~L} 2=90^{\circ}, 270^{\circ}$

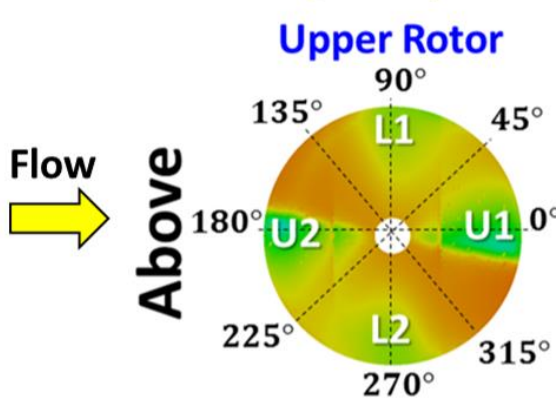

Upper Rotor

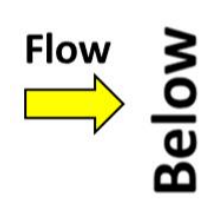

Lower Rotor

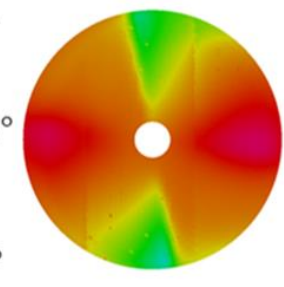

Lower Rotor

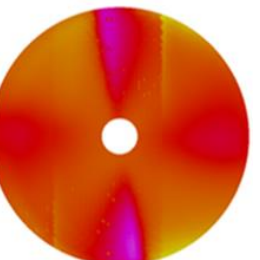$$
\text { Pressure }\left(\frac{l b}{f t^{2}}\right)
$$

2110

2120

Figure 5: HC1 flow field absolute pressures below and above rotor at two instances in time for a) upper rotor where $\mathrm{U} 1, \mathrm{U} 2=0^{\circ}, 180^{\circ}$ and b) lower rotor, where L1, L2 $=90^{\circ}, 270^{\circ}$ (RotUNS forward flight DBM calculations). a)

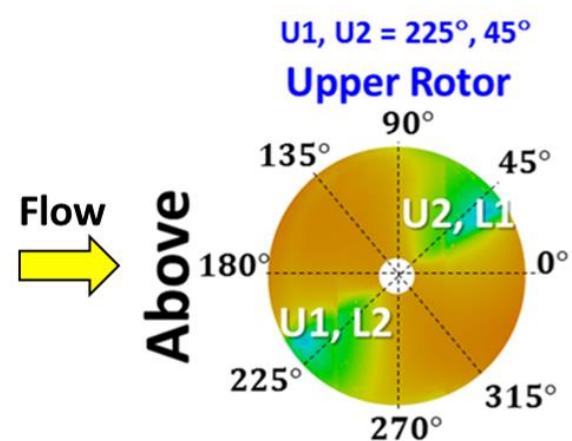

b)

$\mathrm{L} 1, \mathrm{~L} 2=45^{\circ}, 225^{\circ}$

Lower Rotor

Upper Rotor

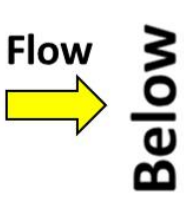

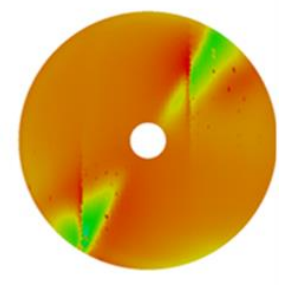

Lower Rotor

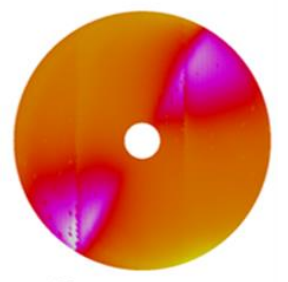

$$
\text { Pressure }\left(\frac{l b}{f t^{2}}\right)
$$

2120
Figure 6: $\mathrm{HC} 1$ flow field absolute pressures below and above rotor at two instances in time for a) upper rotor where $\mathrm{U} 1, \mathrm{U} 2=225^{\circ}, 45^{\circ}$ and b) lower rotor, where L1, L2 $=45^{\circ}, 225^{\circ}$ (RotUNS forward flight DBM calculations).

\section{Lower Rotor \\ Pressure Above \\ $\mathrm{L} 1, \mathrm{~L} 2=90^{\circ}, 270^{\circ}$}

\section{a) Forward Flight}

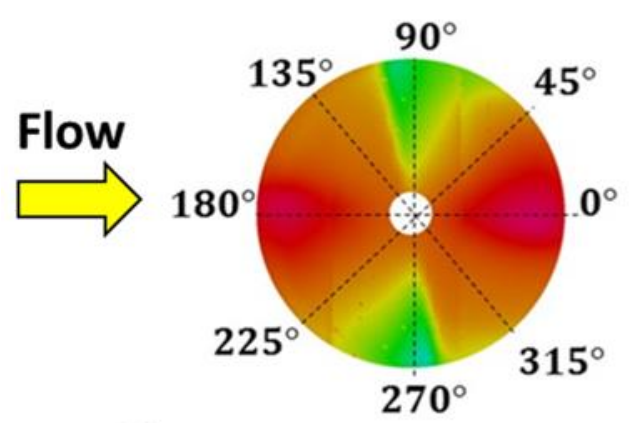

b) Hover

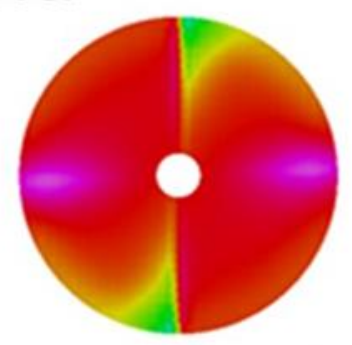

\section{Pressure}

\section{Low}

High

Figure 7: HC1 rotor flow field absolute pressures above lower rotor blades where L1, L2 $=90^{\circ}, 270^{\circ}$ for a) forward flight and b) hover (RotUNS DBM calculations).

Moving beyond the simple coaxial system simulated by BUNNIBITE, RotUNS was next used to study the pressure field of $\mathrm{HCl}$. The absolute pressure below and above each rotor of $\mathrm{HC} 1$ is presented in Figs. 5 and 6 . In both figures the pressure above the upper rotor is the top-left figure and the pressure below the upper rotor is the bottomleft figure. The pressures above and below the lower rotor are represented by the upper- and lower-right figures, respectively.

Figure 5 shows an instance when the blades of the upper and lower rotor are not overlapped. The upper rotor blades are at $0^{\circ}$ (U1) and $180^{\circ}$ (U2) and the lower rotor blades are at $90^{\circ}$ (L1) and $270^{\circ}$ (L2). The presence of the lower rotor is seen at $90^{\circ}$ and $270^{\circ}$ in the upper rotor pressure contours, which reveals the influence of the pressure above the lower rotor. The same is also shown for the pressure above and below the lower rotor, where the pressure below the upper rotor is seen at $0^{\circ}$ and $180^{\circ}$. For the upper rotor, the blades (U1, U2) experience a lower pressure above and higher pressure below, resulting in a positive upward thrust. A similar result is shown for L1 and L2.

Figure 6 shows an instance when the upper and lower blades are overlapped at $45^{\circ}$ (U1) and $135^{\circ}$ (U2) for the upper rotor and $45^{\circ}$ (L1) and $225^{\circ}$ (L2) for the lower rotor. Compared to Fig. 5, the pressure above and below the upper rotor decreases when the blades overlap. 
The opposite is seen for the lower rotor, where the pressure above and below increase compared to the non-overlapped case (Fig. 5).

The RotUNS HC1 calculations reveal that at the time of blade crossing the lower rotor blades enter a region of high pressure due to the pressure below the upper rotor (high pressure), and in turn an overall increase in absolute pressure on the lower rotor blades is seen. Also at the time of blade crossing, the upper rotor blades enter a region of lower pressure due to the pressure above the lower rotor (low pressure), the upper rotor blades see an overall decrease in absolute pressure at this time.

Previously, Barbely et al. [6] analyzed the pressure distribution above and below the upper and lower rotor in hover for $\mathrm{HC} 1$. The pressure above the lower rotor in forward flight and hover is shown in Fig. 7 with the lower rotor blades previously at $90^{\circ}$ and $270^{\circ}$. The pressure scales for the hover and forward flight case are different. The pressure field in hover is symmetrical, while the forward flight case is not.

To help deconstruct and confirm the pressure field results of RotUNS, OVERFLOW simulations of two airfoils traveling in opposite directions were performed. Table 4 lists the four cases simulating two blades separated vertically by a distance $S$, traveling in opposite directions. For each case the lower and upper airfoil are traveling at the same speed, which simulates hover. Beyond this paper, airfoils crossing at two different speeds will be calculated and analyzed to simulate forward flight.

As shown in Table 4, Case 1 and Case 2 simulate the airfoil geometry and flow conditions of $\mathrm{HCl}$ at $\mathrm{r} / \mathrm{R}=1.0$, with a chord of $0.375 \mathrm{ft}$ at Mach 0.47. Mach 0.47 is representative of the advancing tip Mach $\left(\mathrm{M}_{\text {tip }}\right)$ number of $\mathrm{HCl}$ for advance ratio of 0.12 . Case 1 is for a separation distance of $0.5 \mathrm{ft}$, while Case 2 is for a separation distance of $2.33 \mathrm{ft}$, similar to $\mathrm{HC} 1$. Separation distance was varied to understand the effect on the flow field.

Table 4: Conditions for 2D OVERFLOW simulation.

\begin{tabular}{|c|c|c|c|c|c|c|}
\hline Case & $\mathrm{c}(\mathrm{ft})$ & $\mathrm{S}(\mathrm{ft})$ & $\mathrm{S} / \mathrm{c}$ & $\mathrm{M} \infty$ & $\alpha\left(^{\circ}\right)$ & $\mathrm{Re}$ \\
\hline 1 & 0.375 & 0.50 & 1.33 & 0.47 & 7 & $1.25 \times 10^{6}$ \\
\hline 2 & 0.375 & 2.33 & 6.22 & 0.47 & 7 & $1.25 \times 10^{6}$ \\
\hline 3 & 0.375 & 0.50 & 1.33 & 0.90 & 7 & $2.40 \times 10^{6}$ \\
\hline 4 & 0.375 & 2.33 & 6.22 & 0.90 & 7 & $2.40 \times 10^{6}$ \\
\hline
\end{tabular}

Cases 3 and 4 simulate extreme flow conditions out side of the $\mathrm{HC} 1$ flight envelope to investigate possible shock-shock interactions. Similar to Case 1 and 2, two different separation distances are analyzed. All cases used the NACA0012 geometry.

Figure 8 shows lift and drag results for Cases 1 and 2. As expected, the mutual interaction of the airfoils is more noticeable for $\mathrm{S} / \mathrm{c}=1.33$ (Case 1) than for Case $2(\mathrm{~S} / \mathrm{c}=6.22)$ as the airfoils approach each other. The upper airfoil for Case 1 and Case 2 sees a more dramatic change in $c l$ and $c d$ as the airfoils approach each other. Figure 9 shows results for the same conditions as Fig. 8 except the Mach number has been increased from $\mathrm{M}=0.47$ to 0.90 . The same conclusion as stated for Case 1 and Case 2 holds for Case 3 and Case 4 but the interaction is magnified. The change in $\mathrm{Cl}$ and $c d$ occurs over a smaller time interval due to the increase in speed for the larger separation distance.

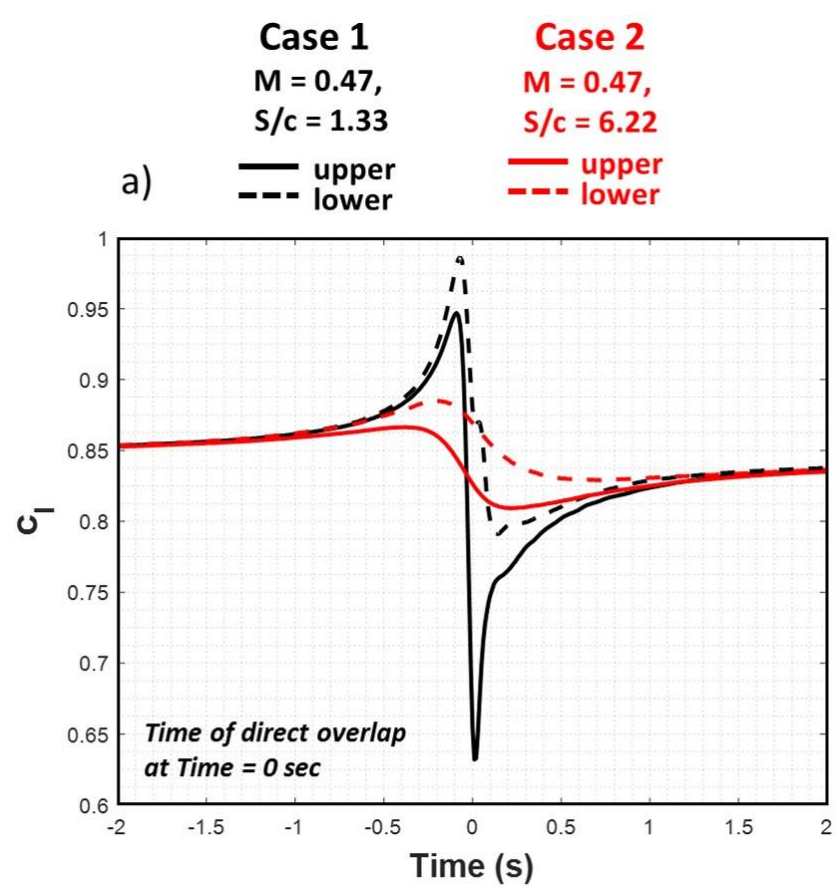

b)

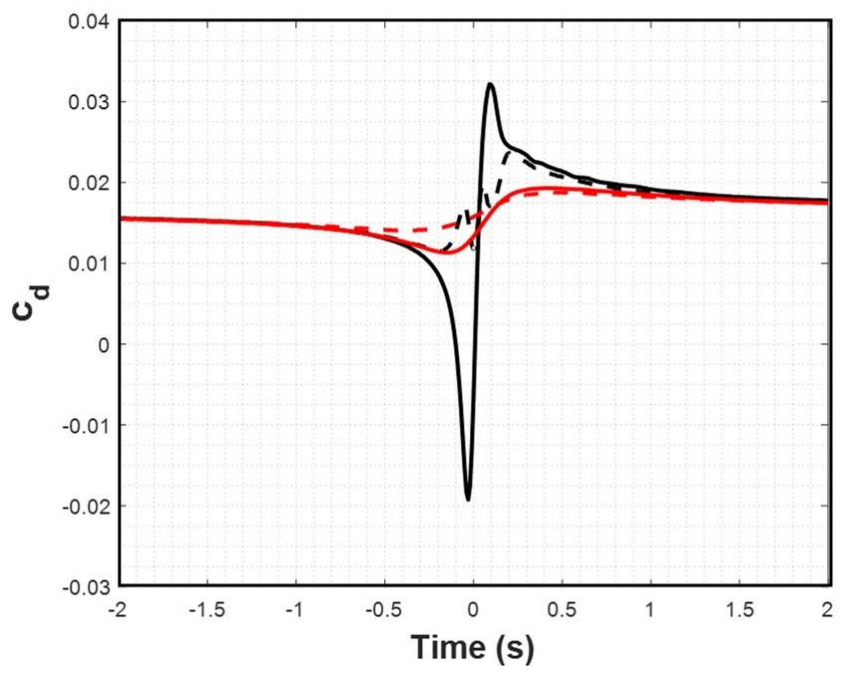

Figure 8: Results from 2D simulation of two NACA0012 airfoils passing each other for $\alpha=7^{\circ}, \mathrm{M}=0.47$, a) $\left.c_{l} \mathrm{~b}\right) c_{d}$. 


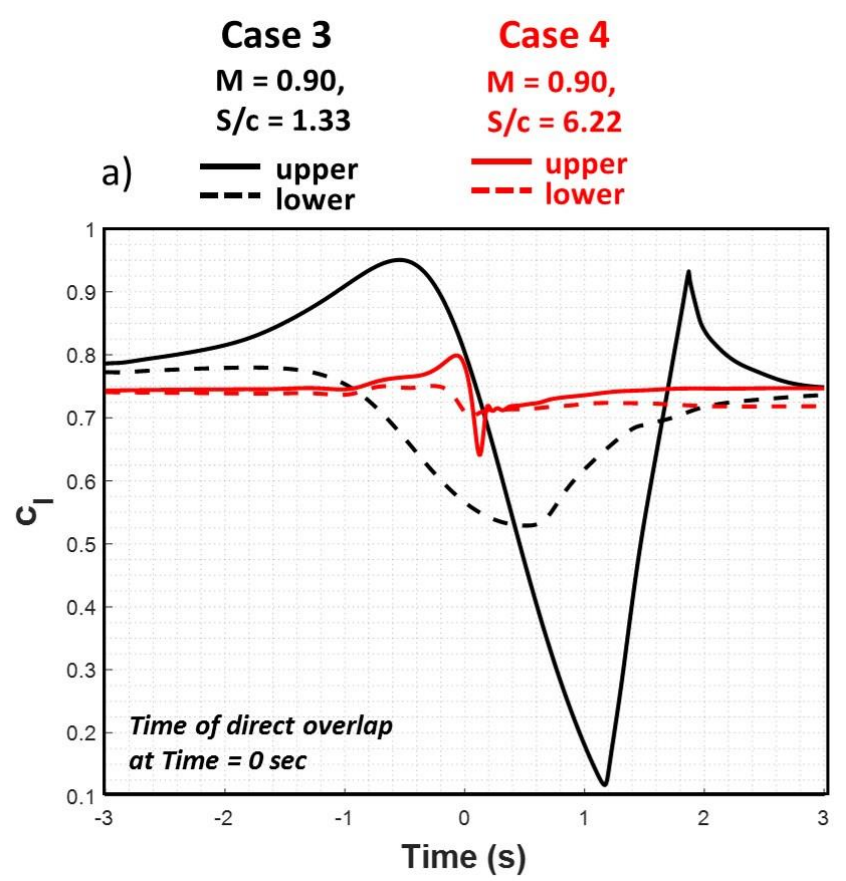

b)

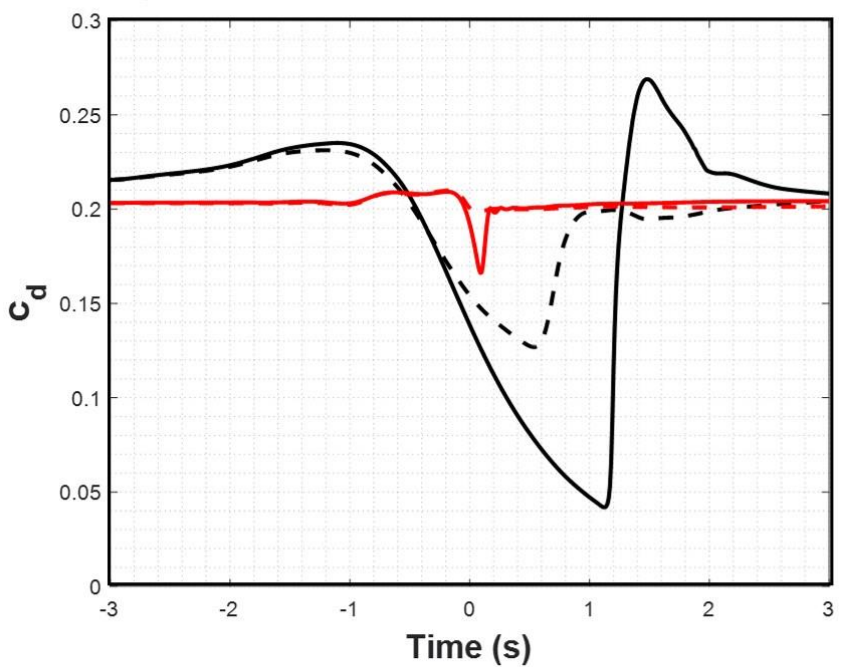

Figure 9: Results from 2D simulation of two NACA0012 airfoils passing each other for $\alpha=7^{\circ}, \mathrm{M}=0.90$, a) $c_{l}$ b) $c_{d}$.

\section{Coaxial rotor wakes}

Transition from hover to forward flight introduces different aerodynamic phenomena. For hover, the wake is beneath the rotor, and as the rotor transitions to forward flight the wake is pushed back in the opposite direction of the flight path. The angle at which the wake is directed is the skew angle. An approximation of the skew angle can be calculated using momentum theory for a single rotor [14] and a coaxial rotor. Using momentum theory for a coaxial rotor, an interference-induced power fact or (Kint) of 1.1412 is used to calculate skew angle (Case 1, [15]) [16], see equation (2). Figure 10 shows the BEMT -based skew angle for HS1 and $\mathrm{HC} 1$ for various advance ratios.

Page 7 of 10

$$
\begin{gathered}
\lambda_{\mathrm{i}}=\mu \tan \left(\alpha_{s}+\kappa_{i n t} \frac{C_{T}}{2 \sqrt{\mu^{2}+\lambda_{i}^{2}}}\right) \\
\chi_{T P P=\tan ^{-1}\left(-\frac{\mu}{\lambda_{i}}\right)}
\end{gathered}
$$

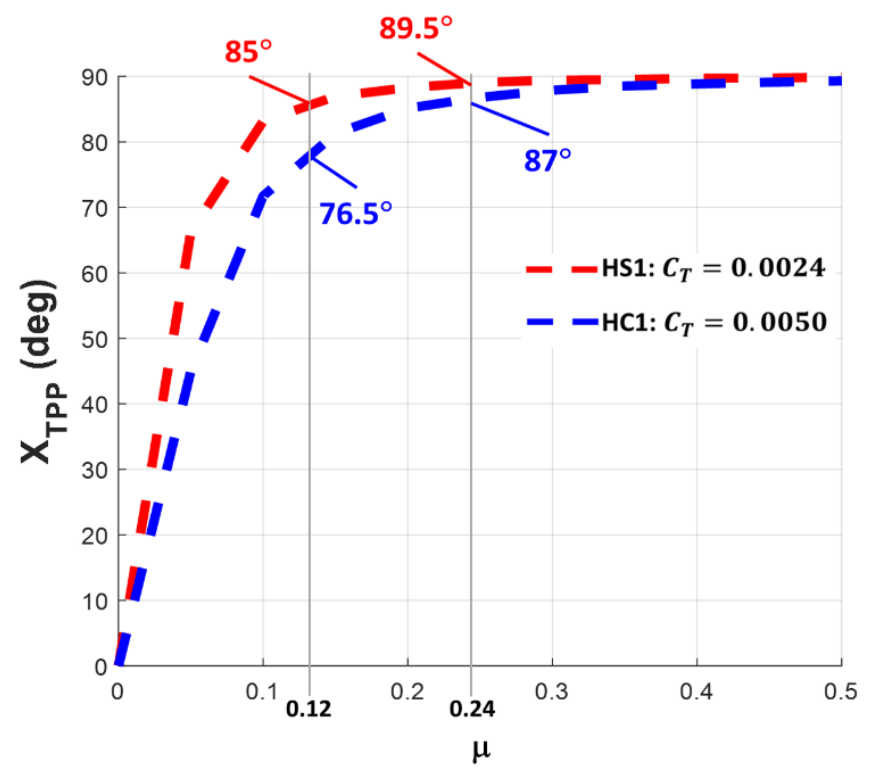

Figure 10: Forward flight skew angle computed using BEMT for HS1 at $\mathrm{C}_{\mathrm{T}}$ $=0.0024$ for $\alpha_{\mathrm{s}}=-2.18^{\circ}$ and $-7.57^{\circ}$ and $\mathrm{HC} 1$ at $\mathrm{C}_{\mathrm{T}}=0.0025$ for $\alpha_{\mathrm{s}}=-2.16^{\circ}$ and $-7.53^{\circ}$.

Using RotUNS calculations, the skew angle is determined from the angle between the $\mathrm{x}$-horizontal and vorticity contours, denoted by the solid white $\mathrm{x}$-axis line and yellow dotted line, respectfully, in Fig. 11. Figures 11 and 12 show skew angle for $\mathrm{HS1}$ and $\mathrm{HC} 1$, respectively, as determined from the RotUNSflow field.

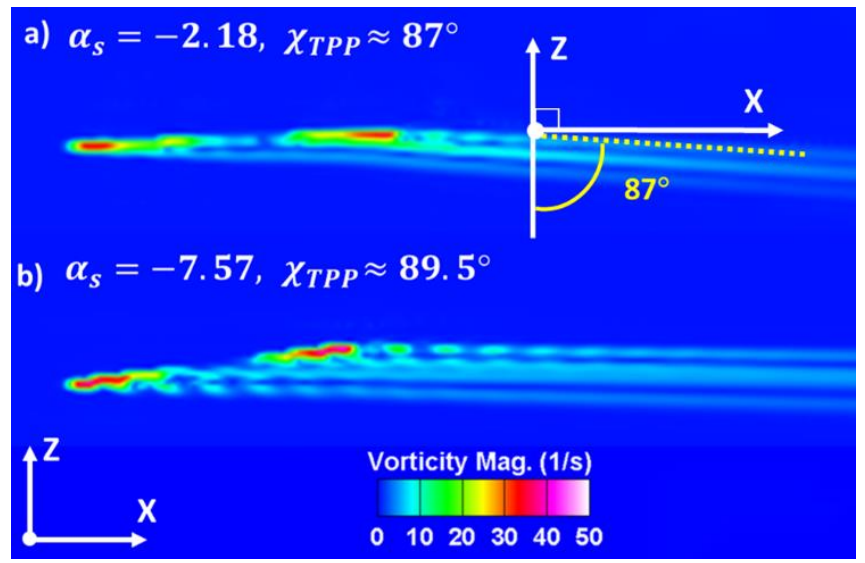

Figure 11: RotUNS DBM calculations of forward flight vorticity magnitude and skew angle for $\mathrm{HS} 1$ where $\mathrm{B} 1, \mathrm{~B} 2=0^{\circ}, 180^{\circ}$ for $\mathrm{C}_{\mathrm{T}}=0.0024$ at a) $\mu=$ $0.12, \alpha_{\mathrm{s}}=-2.18^{\circ}$ and b) $\mu=0.24, \alpha_{\mathrm{s}}=-7.57^{\circ}$. 


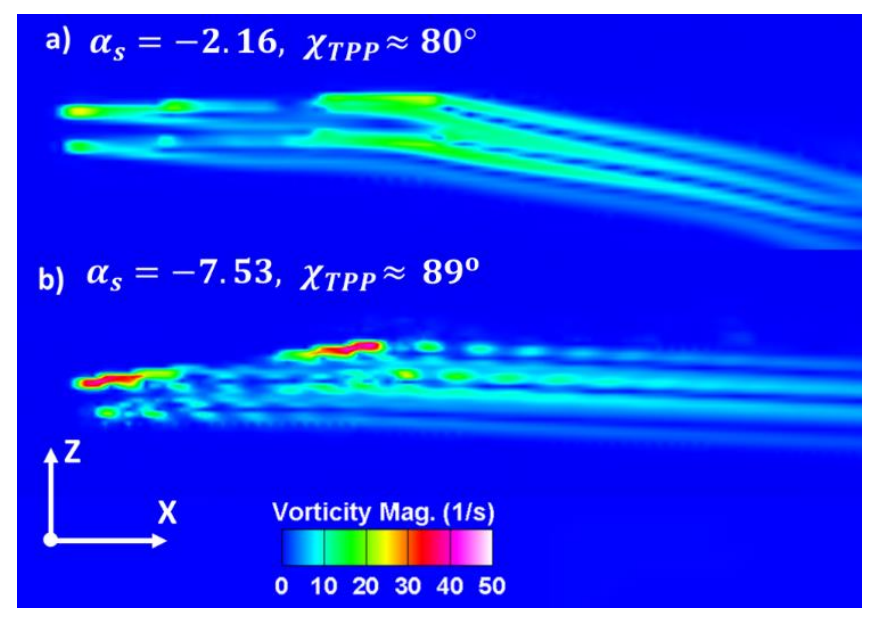

Figure 12: RotUNS DBM calculations of forward flight vorticity magnitude and skew angle for $\mathrm{HC} 1$ where $\mathrm{U} 1, \mathrm{U} 2, \mathrm{~L} 1, \mathrm{~L} 2=0^{\circ}, 180^{\circ}, 90^{\circ}$, and $270^{\circ}$ for $\mathrm{C}_{\mathrm{T}}=0.0025$ a) $\mu=0.12, \alpha_{\mathrm{s}}=-2.16^{\circ}$ and b) $\mu=0.24, \alpha_{\mathrm{s}}=-7.53^{\circ}$.

Table 5 shows a comparison for HS1 and HC1 skew angle calculated for $\mu=0.12$ and 0.24 using BEMT and RotUNS. Using the skew angle $\left(87^{\circ}\right)$ calculated from Blade Element Momentum Theory (BEMT) for $\mathrm{HC1}$ at an advance ratio of 0.24, BUNNIE-BITE predicted four blade crossings and no BVI instances. Using the RotUNS calculation (Fig. 12 a)) with a skew angle of $80^{\circ}$, BUNNIEBITE predicted 2 BVI instances, with blade vortex applied to U1 only (see Figs. 3 and 4). Due to the course grid and tip vortex dissipation, no occurrences of BVI can be discerned from the RotUNS flow field calculations.

Table 5: Momentum Theory vs. RotUNS skew angle calculations

\begin{tabular}{|c|c|c|c|c|}
\hline & $\mu$ & $\alpha s\left({ }^{\circ}\right)$ & $\mathrm{C}_{T}$ & $\chi_{T P P}\left({ }^{\circ}\right)$ \\
\hline \multicolumn{5}{|l|}{ HS1 } \\
\hline \multirow{2}{*}{$B E M T$} & 0.12 & -2.18 & 0.0024 & 85.0 \\
\hline & 0.24 & -7.57 & 0.0024 & 89.5 \\
\hline \multirow{2}{*}{ RotUNS } & 0.12 & -2.18 & 0.0024 & 87.0 \\
\hline & 0.24 & -7.57 & 0.0024 & 89.5 \\
\hline \multicolumn{5}{|l|}{ HC1 } \\
\hline \multirow{2}{*}{$B E M T$} & 0.12 & -2.16 & 0.0050 & 76.5 \\
\hline & 0.24 & -7.53 & 0.0050 & 87.0 \\
\hline \multirow{2}{*}{ RotUNS } & 0.12 & -2.16 & 0.0050 & 80.0 \\
\hline & 0.24 & -7.53 & 0.0050 & 89.0 \\
\hline
\end{tabular}

Vortex diffusion is a critical issue with all computational simulations of rotor wakes. Using resolution enhancements in the grid, vortices can be preserved longer. Kim and Brown [17] conducted a computational investigation using the Vorticity Transport Model (VTM) developed by Brown while coupled with a lifting-line representation of the blade. Without the use of grid adaption in RotUNS, the tip vortices are not discernible after approximately 120 degrees of vortex age. RotUNS offers a Grid Adaption (GA) option. Grid adaption, based on vorticity, was used in the anticipation of the complex interaction between the upper and lower rotor. The use of GA redefines and refines the mesh over time, allowing flow feat ures to be captured with greater fidelity.

RotUNS was run with grid adaption (GA) applied up to 2.5 rotor radii away from the center of the rotor for $\mathrm{HS} 1$ and $\mathrm{HC} 1$ (see Fig. 13). The wake for both $\mathrm{HS} 1$ and $\mathrm{HC} 1$ are discernible up to 3 rotor revolutions. a)

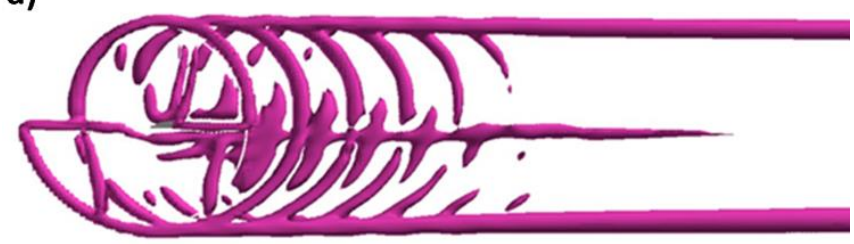

b)

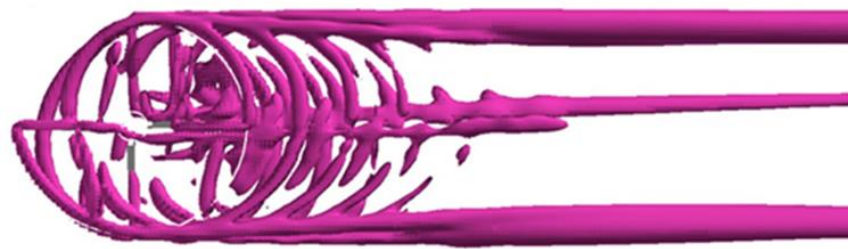

Figure 13: Forward flight Q-criterion of 0.0005 for a) HS 1 where B1, B2 = $\left.90^{\circ}, 270^{\circ} \mathrm{b}\right) \mathrm{HC} 1$ where $\mathrm{U} 1, \mathrm{U} 2=0^{\circ}, 180^{\circ}$ and $\mathrm{L} 1, \mathrm{~L} 2=90^{\circ}, 270^{\circ}(\mu=0.12$, $\left.\mathrm{C}_{\mathrm{T}}=0.0025, \alpha_{\mathrm{s}}=-2.16^{\circ}\right)$.

As mentioned before, no occurrences of BVI can be discernible from RotUNS flow field calculations with the current grid adaption setting. In the future a higher refinement will be attempted to preserve the vorticity.

\section{Concluding Remarks}

Coaxial rotors are finding increased use in todays advanced rotorcraft concepts. The close proximity of the two contra-rotating rotors give rise to many possible aerodynamic interactions and therefore present a challenging problem to analyze. The present work applies simple models, 2D CFD, and 3D CFD to investigate some of the aerodynamic interactions of a coaxial rotor system.

Forward flight performance predictions using Rot UNS for HS1 and $\mathrm{HC} 1$ are calculated using a momentum disk (DSM) and a discrete blade model (DBM). RotUNS calculations for HS1 were closer to the experimental dat a compared to CAMRAD II calculations, while CAMRAD II calculations for $\mathrm{HC} 1$ are closer to measured data compared to RotUNS HC1 calculations.

RotUNS computed absolute pressures above and below each of the HC1 rotors are consistent with 2D OVERFLOW simulations of two airfoils, separated vertically, traveling in opposite directions. A change in lift and drag is seen for both airfoils as the airfoils are in proximity of one another. A more pronounced change in lift and drag is seen for conditions at closer separation distances and increased Mach numbers.

A MATLAB-based tool was developed to predict the time and location of blade overlap and blade-vortex intersections of two contra-rotating rotors. Comparisons with RotUNSresults were not possible, however, because the locations of discrete vortices were not discernible. Additional studies of the RotUNS wake grid are necessary to preserve the vorticity.

For HS1, BEMT skew angle calculations correlated better with RotUNS flow field calculations in comparison to $\mathrm{HC1}$. The skew angle at the lower advance ratio $(\mu=0.12)$ was higher compared to the higher advance ratio $(\mu=0.24)$ for both HS1 and HC1. 


\section{References}

1. Coleman, C. P., "A Survey of Theoretical and Experimental Coaxial Rotor Aerodynamic Research,”NASA TP-3675, NASA, March 1997.

2. Taylor, M. K., "A balsa-dust technique for air-flow visualization and its application to flow through model helicopter rotors in static thrust," NACA T N-2220, NACA, November 1950.

3. Ramasamy, M., "Measurements Comparing Hover Performance of Single, Coaxial, T andem, and TiltRotor Configuration s," American Helicopter Society 69th Annual Forum, Phoenix, AZ, May 21-23, 2013.

4. Cameron, C. G., Uehara, D., and Sirohi, J., "Transient Hub Loads and Blade Deformation of a Mach-Scale Coaxial Rotor in Hover," AIAA Science and Technology Forum and Exposition, SciT ech, Orlando, FL, January 5-9, 2015.

5. Walsh, D., Weiner, S., Arifian, K., Lawrence, T., Wilson, M. Millott, T., and Blackwell, R., "High Airspeed Testing of the Sikorsky X2 Technology Demonstrator," American Helicopter Society 67th Annual Forum, Virginia Beach, VA, May 3-5, 2011.

6. Barbely, N. L., Komerath, N. M., and Novak, L. A., "A Study of Coaxial Rotor Performance and Flow Field Characteristics," American Helicopter Society Aeromechanics Specialist's Conference, San Francisco, CA, January 20-22, 2016.

7. Harrington, R. D., "Full-scale-tunnel investigation of the staticthrust performance of a coaxial helicopter rotor," NACA TN2318, NACA, March 1951.

8. Dingeldein, R. C., "Wind-tunnel studies of the performance of multirotor configurations," NACA TN-3236, NACA, August 1954.

9. Rajagopalan, R. G., Baskaran, V., Hollingsworth, A., Lestari, A., Garrick, D., Solis, E., and Hagerty, B., "RotCFD-A T ool for Aerodynamic Interference of Rotors: Validation and Capabilities," American Helicopter Society Aeromechanics Specialist's Conference, San Francisco, CA, January 18-20, 2012.

10. Guntupalli, K., Novak, L. A., and Rajagopalan, R. G., "RotCFD: An Int egrated Design Environment for Rotorcraft," American Helicopter Society Aeromechanics Specialist's Conference, San Francisco, CA, January 20-22, 2016.

11. Nichols, R. and Buning, P., User's Manual for OVERFLOW 2.2, NASA Langley Research Center, Hampton, VA, August 2010.

12. Johnson, W., "Influence of Lift Offset on Rotorcraft Performance," NASA TP - 215404, NASA, November 2009.

13. MATLAB, version 7.10.0 (R2010a), The MathWorks Inc., Natick, Massachusetts, 2010.

14. Leishman, J. G., Principles of Helicopter Aerodynamics, Cambridge University Press, New York, NY, 2000, Chapter 10.

15. Leishman, J. G. and Syal, M., "Figure of Merit Definition for Coaxial Rotors," Journal of the American Helicopter Society, Vol. 53, (3), July 2008, pp. 290-300.

16. Ma, Y., Chen, M., Zhang, X., and Wang, Q., "Scale model tests of coaxial rotors in water tunnel via particle image velocimetry technique," Journal of Aerospace Engineering, 2015.

17. Kim, H. W. and Brown, R. E., "Computational Investigation of Small Scale Coaxial Rotor Aerodynamics in Hover," American Helicopter Society 62nd Annual Forum, Phoenix, AZ, May 911,2006

\section{Contact Information}

Natasha Barbely

NASA Ames Research Center

Mail Stop: 243R-11

Moffett Field, CA 94035-0001

Email: Natasha.L.Barbely@nasa.gov

Office: (650) 604-5903

\section{Acknowledgments}

The authors would like to thank the U. S. Army Aviation Development Directorate (ADD), with personal thanks to Dr. William Warmbrodt (NASA), Dr. Gloria Yamauchi (NASA) and Mr. Ethan Romander (NASA). Dr. Kenneth Brentner (The Pennsylvania State University) is also acknowledged for his support and advice in the research.

\section{Nomenclature}

\begin{tabular}{|c|c|}
\hline$A$ & rotor disk area $\left(\pi R^{2}\right),\left(\mathrm{ft}^{2}\right)$ \\
\hline $\mathrm{B}_{1}$ & single rotor blade 1 \\
\hline $\mathrm{B}_{2}$ & single rotor blade 2 \\
\hline C & $\operatorname{chord}(\mathrm{ft})$ \\
\hline$C_{d}$ & coefficient of drag $\left(\frac{d r a g}{\frac{1}{2} \rho V^{2} c}\right)$ \\
\hline$C_{1}$ & coefficient of lift $\left(\frac{\text { lift }}{\frac{1}{2} \rho V^{2} c}\right)$ \\
\hline$C_{P}$ & rotor power coefficient $\left(\frac{P}{\rho V_{\text {tip }}^{3} A}\right)$ \\
\hline$C_{p}$ & coefficient of pressure, $\left(\frac{p-p_{\infty}}{\frac{1}{2} \rho V^{2}}\right)$ \\
\hline $\mathrm{C}_{\mathrm{T}}$ & rotor thrust coefficient $\left(\frac{T}{\rho V_{\text {tip }}^{2} A}\right)$ \\
\hline $\mathrm{L}_{1}$ & lower rotor blade 1 \\
\hline $\mathrm{L}_{2}$ & lower rotor blade 2 \\
\hline M & Mach number \\
\hline $\mathrm{M}_{\text {tip }}$ & tip Mach number \\
\hline $\mathrm{N}_{\mathrm{b}}$ & number of blades (per rotor) \\
\hline$P$ & rotor power $(\mathrm{Hp})$ \\
\hline Q & torque $(\mathrm{lb}-\mathrm{ft} / \mathrm{s})$ \\
\hline $\mathrm{R}$ & rotor radius $(\mathrm{ft})$ \\
\hline
\end{tabular}


$r / R$ nondimensional radial position

$\mathrm{T} \quad$ rotor thrust (lb)

$\mathrm{U}_{1} \quad$ upper rotor blade 1

$\mathrm{U}_{2} \quad$ upper rotor blade 2

V forward flight velocity (ft/s)

$V_{\text {tip }} \quad$ blade tip speed (ft/s)

$\mathrm{S} \quad$ vertical distance between rotors or airfoils ( $\mathrm{ft}$ )

$\alpha_{\mathrm{S}} \quad \begin{aligned} & \text { airfoil/rotor shaft angle (deg), negative pitch } \\ & \text { down }\end{aligned}$

$\mathrm{K}_{\text {int }}$ coaxial rotor induced power interference fact or

$\lambda_{\mathrm{i}} \quad$ inflow (ft/s) $\mu \quad$ advance ratio $\left(\mathrm{V} / \mathrm{V}_{\text {tip }}\right)$

$\rho \quad$ density of air (slugs/ $/ \mathrm{ft}^{3}$ )

$\sigma \quad$ rotor solidity $\left(\frac{N_{b} c}{\pi R}\right)$

$\theta \quad$ rotor collective pitch angle (deg)

$\theta_{1 \mathrm{c}} \quad$ rotor lateral cyclic pitch (deg)

$\theta_{1 \mathrm{~s}} \quad$ rotor longitudinal cyclic pitch (deg)

$\chi_{T P P} \quad$ wake skew angle $(\mathrm{deg})$ 